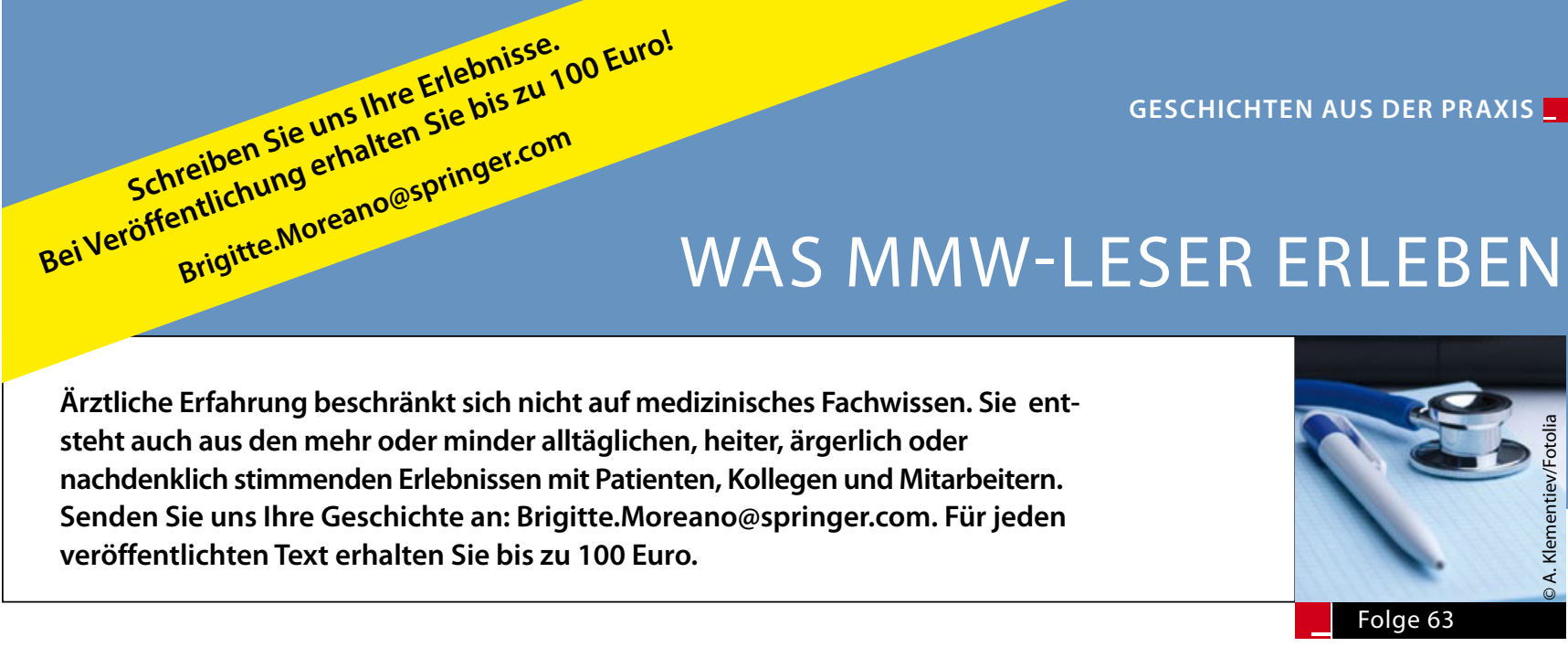

\title{
Ein nicht ganz so leichter Fall
}

- Vor einigen Monaten habe ich meine eigene Praxis eröffnet. Gleich von Anfang an kam ein Patient mittleren Alters mit Hüftgelenksbeschwerden, die bereits mehrfach abgeklärt waren. „Chronische Ansatztendinitis" lautete die Diagnose des Orthopäden. Nun sollte ich mit Akupunktur ran, um seine immer wiederkehrenden Schmerzen zu lindern. Außerdem berichtete der Patient über eine chronische Arbeitsüberlastung als Selbständiger in der Papierbranche. Nervlich war er oft angespannt, schlief in letzter Zeit schlecht und war oft gereizt.

Ein nicht ganz so leichter Fall, dachte ich. Er kam zweimal wöchentlich zur Akupunktur. Jedes Mal unterhielt ich mich mit ihm, er berichtete über die berufliche Überlastung und beklagte sich insgesamt sehr viel. Es war nicht immer leicht, ihm zuzuhören. Die Akupunktur half ihm nur bedingt, er beklagte sich jedes Mal über die noch anhaltenden Schmerzen. Meine Geduld wurde ziemlich strapaziert und ich war langsam selbst genervt.

Dann brach er die Behandlung ab. Er hätte es ja überall versucht, aber kein Arzt könne ihm wirklich helfen. Ich war enttäuscht und habe mich etwas geärgert, hatte ich mir doch soviel Mühe gegeben.

Plötzlich vereinbarte er dann nach einigen Wochen wieder einen Termin für ein Gespräch. In diesem Gespräch legte er mir eine Vorsorge- und Betreuungsvollmacht zusätzlich zur Patientenverfügung vor. $\mathrm{Er}$ sagte, er habe außer seiner Frau keinen Menschen, dem er noch vertrauen könnte und er würde mich gerne an zweiter Stelle auf die Vorsorge und Betreuungsvollmacht setzen. Er habe durch die vielen Gespräche während der Akupunkturen gesehen, wie viel ihm dies gebracht hätte (!), und dass er ein sehr großes Vertrauen mir gegenüber habe. Dies wolle er würdigen und daher diese eher ungewöhnliche Bitte.

Ich fühlte mich geehrt und sagte ihm dies auch, es freute mich wirklich, nach all den Wochen des Beklagens. Dennoch habe ich das Angebot nicht angenommen. Es ist mir zu persönlich und rechtlich zu riskant. Aber trotzdem hat mich diese "wundersame Wendung" sehr gefreut. So kann man im ärztlichen Alltag manchmal überrascht werden ...

DR. MED. ISABEL BLoSS, ETtLINGEN -

\section{Positive Unordentlichkeit}

\section{- Auf der Rückfahrt von Dresden nach} Berlin war ich mit einer jungen Kollegin verabredet, die in demselben Institut arbeitete wie ich. Ich holte sie in einer wenig befahrenen Nebenstraße eines Dresdner Vorortes ab. Wir hatten beide viel Gepäck, und so musste einiges umgelagert und umgepackt werden. Dabei fokussierte ich meine Aufmerksamkeit uneingeschränkt auf die sehr sympathische Kollegin.

Am nächsten Tag vermisste ich meine Aktentasche. Sie enthielt zwei Bände eines Jahrgangs von JAMA, die ich über die Bibliothek meines Instituts entliehen hatte. Ich meldete den Verlust meinem Chef. Das gab einen gepfefferten Anpfiff und das Verbot der Entleihung von Bibliothekseigentum außer Haus. Disziplinarverfah-

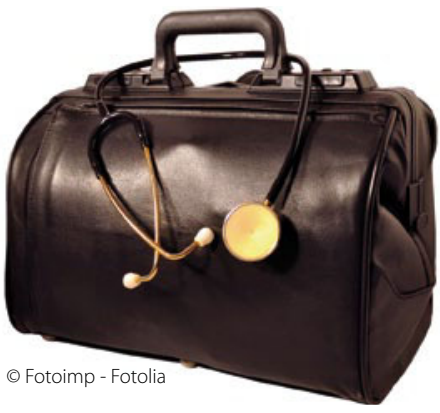

Ich hatte die Angewohnheit gehabt, vor Aufschließen der Autotür mein Handgepäck auf dem Dach abzulegen. So ren, strenger Verweis und Schadenersatzauflagen standen bevor.

Da geschah ein Wunder. Meine Mutter teilte mir telefonisch mit, dass ich die Aktentasche in einem Dresdner Fundbüro abholen könne. In Ermangelung eines ordentlichen Notizbuches hatte ich die Dienst-Telefonnummer meiner Mutter auf die Innenseite der Verschlussklappe meiner Aktentasche geschrieben. ruhte meine Aktentasche auch diesmal wieder auf dem Autodach, von dem sie wenige Meter nach dem Anfahren heruntergerutscht war.

Ach ja, die junge sympathische Kollegin: Die habe ich ein halbes Jahr später geheiratet. Vor einiger Zeit haben wir unsere Goldene Hochzeit gefeiert.

DR. MED. E. TÖPPICH, ULLERSDORF * 